\title{
Climate change and forests in India: note from the guest editors
}

\author{
N. H. Ravindranath • Asbjorn Aaheim • Jayant Sathaye
}

Received: 30 November 2010 / Accepted: 3 December 2010 /

Published online: 8 January 2011

(C) Springer Science+Business Media B.V. 2011

Forestry is one of the most important sectors in the context of climate change. It lies at the center-stage of global mitigation and adaptation efforts. Yet, it is one of the least understood sectors, especially in tropical zones, which constitute a significant portion of the global forests. Recently, there has been a growing interest in forests in addressing global climate change. The IPCC Assessment Report 4 (2007) Chapters related to forests have highlighted the limited number of studies on the impact of climate change on forests at the regional, national and sub-national level, while policy makers need information at these scales. Further, implication of projected climate change on mitigation potential of forest sector is only briefly mentioned in the IPCC report, with limited literature to support the conclusions. India is one among the top ten nations in the world in terms of forest cover. It is also sixth among the tropical countries in terms of forested area. As IPCC Assessment Report 5 work is about to be initiated soon, studies on the impact of climate change on forests as well as the mitigation potential of the forest sector, particularly at regional and national level, will be of great interest to the scientific and policy community.

In order to conserve the carbon stored in forests and to reduce $\mathrm{CO}_{2}$ emissions from the forest sector, the Reduced Emissions from Deforestation and Degradation (REDD) mechanism is now being finalized under the UNFCCC. In this context, climate change itself may affect the mitigation potential significantly, and it is important to understand how vulnerable the forest carbon stock (biomass and soil) in the tropics is to the projected

\footnotetext{
A. Aaheim

CICERO, Center for International Climate and Environmental Research-Oslo, P.O. Box 1129, Blindern, Oslo 0318, Norway

N. H. Ravindranath $(\bowtie)$

Center for Sustainable Technology, Indian Institute of Science, Bangalore 560 012, India e-mail: ravi@ces.iisc.ernet.in

J. Sathaye

International Energy Studies, Lawrence Berkeley National Laboratory, Berkeley, California, US e-mail: JASathaye@lbl.gov
}

N. H. Ravindranath

Divecha Center for Climate Change, Indian Institute of Science, Bangalore 560 012, India 
climate change. In fact, there is a need to study the impact of climate change on forests for all the major forested countries.

This special issue of Mitigation and Adaptation Strategies to Global Change aims to address key issues related to impacts of climate change on forests. The papers deal with the impacts of climate change on forest types and distribution, net primary productivity and mitigation potential, and address the potential adaptation strategies and the implications of policies to exposure of forests to climate change risks. All the eight papers of this special issue focus on India, a key tropical forested country. This special issue fills a major knowledge gap on climate change studies at regional and major country levels, since forest management decisions are taken at national and sub-national levels.

The first paper (Chaturvedi et al.: Impact of climate change on Indian forests: a dynamic vegetation modelling approach) uses a dynamic global vegetation modeling based approach to assess the impact of climate change on Indian forests. The IBIS model-based study shows that about $39 \%$ and $34 \%$ of forests in India are projected to be impacted under A2 and B2 scenarios, respectively, towards the end of the century. A spatial vulnerability map is also constructed for Indian forests, using the impact projections and other ground-data (such as forest density). The second paper (Bala et al.: $\mathrm{co}_{2}$-fertilization and potential future terrestrial carbon uptake in India) investigates the bounds on terrestrial carbon uptake over India that arises solely due to the phenomenon of $\mathrm{CO}_{2}$ fertilization. The model simulations imply that the maximum potential terrestrial sequestration over India, under equilibrium conditions and best case scenario of unlimited $\mathrm{CO}_{2}$-fertilization, is only $18 \%$ of the $21 \mathrm{st}$ century SRES A2 scenario projected emissions from India.

The next paper (Murthy et al.: Climate change and forests in India: adaptation opportunities and challenges) presents an approach to the development of an adaptation framework, and discusses resulting policy strategies and practices needed for mainstreaming adaptation to cope with projected climate change. Afreen et al., (Forest policies and programs affecting vulnerability and adaptation to climate change) present a review of the forest policies and programs and study their implications for the status of forests and for vulnerability of forests to projected climate change. A species-level assessment of effect of climate change is made by Gopalakrishnan et al., (Impact of climate change at species level: a case study of teak in India). They describe the long-term effect of climate change on commercially important teak (Tectona grandis) species and its productivity in India. Ravindranath et al., (Implications of climate change on mitigation potential estimates for forest sector in India) estimate the national level forest sector mitigation potential, factoring in the effects of climate change. In this study, climate change impacts of two popular global vegetation models (BIOME and IBIS) are used to assess the implications for mitigation.

A subsequent paper (Aaheim et al.: A macroeconomic analysis of adaptation to climate change impacts on forests in India) examines the potential for adaptation to climate change in Indian forests, and derives the macroeconomic implications of forest impacts and adaptation in India. The study is conducted by integrating results from the dynamic global vegetation model IBIS and the computable general equilibrium model GRACE-IN, which estimates macroeconomic implications for six zones of India. The last paper (Aaheim et al:: Integrated modelling approaches to analysis of climate change impacts on forests and forest management) reviews integrated economic and ecological models that address impacts and adaptation to climate change in the forest sector. 